\title{
Toxic effects of ammonia on the survival, growth, and oxidative and immune responses in the Pacific abalone, Haliotis discus hannai
}

\author{
Hee-Ju Park, Young-Bin Yu, Jae-Ho Choi, Ju-Hyeong Lee, Ju-Chan Kang* \\ Department of Aquatic Life Medicine, Pukyong National University, Busan 48513, Korea
}

\begin{abstract}
The accumulation of ammonia, a consequence of intensive aquaculture activity, can damage cultured animals. We analyzed the survival rates, growth, antioxidant responses, and immune responses of abalones, Haliotis discus hannai (mean shell length 70.2 $\pm 4.9 \mathrm{~mm}$; mean body weight $36.9 \pm 3.6 \mathrm{~g}$ ), biweekly for four weeks, to determine the accumulated concentrations of ammonia $(0,0.1,0.2,0.4,0.8$, and $1.6 \mathrm{mg} / \mathrm{L})$. In our biweekly measurements, a survival rate of $\geq 95 \%$ was observed for all concentrations of ammonia. The specific growth rate (SGR) decreased at $\geq 0.8 \mathrm{mg} / \mathrm{L}(p<0.05)$, but the daily increment in shell length (DISL) showed no significant change $(p<0.05)$. Regarding antioxidant responses, the superoxide dismutase (SOD) activity of the hepatopancreas was increased at ammonia concentrations over 0.8 and $0.2 \mathrm{mg} / \mathrm{L}(p<0.05)$ at two and four weeks, respectively, and the SOD activity of the gills increased at concentrations over 0.4 and $1.6 \mathrm{mg} / \mathrm{L}(p<0.05)$ at four weeks. The catalase (CAT) activity of the hepatopancreas and gills increased at ammonia concentrations $>0.8 \mathrm{mg} / \mathrm{L}(p<0.05)$. Phenoloxidase (PO) activity increased at ammonia concentrations over $0.8 \mathrm{mg} / \mathrm{L}(p<0.05)$, and Lysozyme (LZM) increased at concentrations over 0.8 and 0.4 $\mathrm{mg} / \mathrm{L}(p<0.05)$. Overall, our findings indicated that ammonia concentrations over $0.8 \mathrm{mg} / \mathrm{L}$ in seawater might damage the SGR, antioxidant responses, and immune responses in $\mathrm{H}$. discus hannai. Our findings suggest the necessity of improvement or reinstallation for abalone aquaculture systems and can be used to assess the toxic effects of ammonia on $H$. hannai.
\end{abstract}

Keywords: Haliotis discus hannai, Ammonia, Growth performance, Oxidative stress, Immune responses

\section{Introduction}

Ammonia is ubiquitous in aquatic environments because it is created by feed residuals, fertilizers, and animal excretions. Ammonia levels in aquatic environments can be increased by sew- age effluents, industrial wastes, agricultural run-off, and decomposition of biological wastes, as well as high-density aquaculture. High ammonia concentrations have adverse effects on aquatic organisms, such as reduced growth rate, loss of equilibrium, disruption of ion balance, gill hyperplasia, hyperexcitability, coma,

Received: Dec 23, 2020 Revised: Jan 10, 2021 Accepted: Jan 29, 2021

*Corresponding author: Ju-Chan Kang

Department of Aquatic Life Medicine, Pukyong National University, Busan 48513 , Korea

Tel: +82-51-629-5944, Fax: +82-51-629-5938, E-mail: jckang@pknu.ac.kr, ORCID: https://orcid.org/0000-0002-9333-5779

This is an Open Access article distributed under the terms of the Creative Commons Attribution Non-Commercial License (http://creativecommons.org/licenses/by$\mathrm{nc} / 4.0 /$ ) which permits unrestricted non-commercial use, distribution, and reproduction in any medium, provided the original work is properly cited.

Copyright $\odot 2021$ The Korean Society of Fisheries and Aquatic Science 
and convulsions (Li et al., 2013; Pan et al., 2011 ). In aquatic environments, ammonia exists in two chemical forms: an ionized form $\left(\mathrm{NH}_{4}^{+}\right)$and an un-ionized form $\left(\mathrm{NH}_{3}\right)$ (Kim et al., 2015). Of the two chemical forms, $\mathrm{NH}_{3}$ is more toxic to aquatic organisms than $\mathrm{NH}_{4}^{+}$because $\mathrm{NH}_{3}$ can cross the phospholipids of biological membranes (Miron et al., 2008). The permeation of ammonia can trigger oxidative stress, such as a redox imbalance or DNA damage, in aquatic organisms due to an increase in reactive oxygen species (ROS), including singlet oxygen, nitric oxide, hydrogen peroxide $\left(\mathrm{H}_{2} \mathrm{O}_{2}\right)$, and superoxide radicals (Cheng et al., 2015). Many studies have reported that ammonia exposure stimulates the overactivation of N-methyl-d-aspartate glutamate receptors in the brain and neurons, which leads to an overproduction of ROS (Li et al., 2016; Zhang et al., 2018). In addition, excess ROS generation can also damage the respiratory chain of the mitochondrial membrane while increasing the calcium concentration, which in turn induces apoptosis (Zhang et al., 2020). Aquatic organisms have antioxidant enzymes to cope with excess ROS, such as superoxide dismutase (SOD) and catalase (CAT). SOD converts superoxide anion radicals into hydrogen peroxide and oxygen. CAT then decomposes hydrogen peroxide into water and molecular oxygen (Zhang et al., 2020). These antioxidant enzymes protect cells from ROS and maintain redox balance. Therefore, antioxidant responses can be an indicator of the oxidative stress induced by ammonia exposure (Kim et al., 2017).

The immune system of invertebrates can change in response to various changes in environmental conditions, such as temperature, salinity, $\mathrm{pH}$, ammonia, and pollutants (Jiang et al., 2004). Exposure to a high concentration of ammonia is considered to be toxic and can lead to changes in the immune responses of invertebrates, such as phenoloxidase (PO) and lysozyme (LZM). PO is an enzyme involved in the innate immune defense system of invertebrates that plays a role in coagulation, phagocytosis, nodule formation, encapsulation, and antimicrobial peptide synthesis (Chen et al., 2012). PO, a copper-containing enzyme, is an important component of the pro-PO activating reaction cascade, which catalyzes the hydroxylation of monophenols to o-diphenols and the oxidation of odiphenols to o-quinones (Le Clec'h et al., 2016; Yao et al., 2019). In addition to PO, LZM is ubiquitous in hemolymph tissues and secretions and plays an important role in invertebrate immunity by hydrolyzing the 1,4- $\beta$-linkages of bacterial cell walls (Bachali et al., 2002; Ding et al., 2011; Nam et al., 2020). Therefore, both $\mathrm{PO}$ and LZM activity in invertebrates can be used as indicators of immune status by ammonia exposure.

Abalones, a type of marine gastropod, are widely considered a nutritive seafood resource for humans with antioxidant, anti-inflammatory, and anti-cancer effects (Min et al., 2015; Nam et al., 2020; Wickramanayake et al., 2020). The abundance of abalone fisheries globally has declined since the 1970s, whereas abalone aquaculture has been increasing over the past few years, constituting 95\% of abalone production in the world (Cook, 2014; Wickramanayake et al., 2020). As production increases, the reliance on high-protein feed and high-density aquaculture increases; as a result, ammonia may accumulate in the culture water, subjecting abalones to problems related to ammonia toxicity (Naylor et al., 2014). Of the abalone species, Haliotis discus hannai is considered an important species in the Korean shellfish industry because it is highly marketable and commercially valuable. However, there is a lack of research concerning the potentially toxic effects of ammonia on $H$. discus hannai, despite the likelihood of elevated ammonia exposure. Therefore, the present study aimed to investigate the toxic effects of ammonia on the survival rate, growth performance, and antioxidant (SOD and CAT) and immunity responses (PO and LZM activity) in H. discus hannai.

\section{Materials and Methods}

\section{Experimental abalones, culture conditions, and ethics statement}

Juvenile $H$. discus hannai individuals were obtained from an abalone farm in Jeju Island, Korea. Three hundred $H$. discus hannai were acclimatized to a $500 \mathrm{~L}$ cylindrical tank under laboratory conditions for one week (Table 1) and were supplied Undaria pinnatifida as the major diet. The tank was provided with a constant flow of water and maintained under $24 \mathrm{~h}$ dark conditions. After acclimation, fifteen healthy $H$. discus hannai (mean shell length $70.2 \pm 4.9 \mathrm{~mm}$; mean body weight $36.9 \pm$ $3.6 \mathrm{~g}$ ) were randomly selected from the acclimation tank and were divided into six groups. Each group was sorted into a 150 L cylindrical tank. Ammonia chloride $\left(\mathrm{NH}_{4} \mathrm{Cl}\right)$ (Sigma-Aldrich, St. Louis, MO, USA ) solution was dissolved in each tank in the following ammonia concentrations: $0,0.1,0.2,0.4,0.8$, and 1.6 $\mathrm{mg} / \mathrm{L}$. The actual ammonia concentrations are compared with the waterborne ammonia concentrations in Table 2. During the experimental period, water temperature and $\mathrm{pH}$ were continuously measured and maintained at $18 \pm 0.5^{\circ} \mathrm{C}$ and $8.1 \pm 0.2$, respectively. When the water in each tank was renewed once 
Table 1. The chemical components of seawater and experimental condition used in the experiments

\begin{tabular}{ll}
\hline Item & Value \\
\hline Temperature $\left({ }^{\circ} \mathrm{C}\right)$ & $18.0 \pm 0.5$ \\
Salinity $(\% \circ)$ & $33.2 \pm 0.5$ \\
$\mathrm{pH}$ & $8.1 \pm 0.2$ \\
Dissolved oxygen $(\mathrm{mg} / \mathrm{L})$ & $7.2 \pm 0.2$ \\
Chemical oxygen demand $(\mathrm{mg} / \mathrm{L})$ & $1.18 \pm 0.2$ \\
\hline
\end{tabular}

Table 2. Analyzed waterborne ammonia concentration from each source

\begin{tabular}{lllllll}
\hline $\begin{array}{c}\text { Waterborne ammonia } \\
\text { concentrations (mg/L) }\end{array}$ & 0.0 & 0.1 & 0.2 & 0.4 & 0.8 & 1.6 \\
\hline $\begin{array}{c}\text { Actual ammonia } \\
\text { concentrations (mg/L) }\end{array}$ & 0.02 & 0.13 & 0.24 & 0.42 & 0.83 & 1.64 \\
\hline
\end{tabular}

daily, the $\mathrm{pH}$ and ammonia concentration were adjusted using a pH meter (Model 9625, Horiba, Kyoto, Japan ) and adding $\mathrm{NH}_{4} \mathrm{Cl}$ solution, respectively. The water was continuously aerated using an air pump. A sufficient amount of $U$. pinnatifida was supplied daily, and the remaining $U$. pinnatifida were removed at the time of water renewal.

The total exposure duration was four weeks, and the experiments were conducted at two and four weeks. Six experimental individuals were selected from each tank and anesthetized in buffered 3-aminobenzoic acid ethyl ester ethanesulfonate (Sigma-Aldrich). The $H$. discus hannai were maintained under a protocol approved by the Institutional Animal Care and Use Committee of Pukyong National University.

\section{Survival rates}

To determine the survival rates, the H. discus hannai were transferred into each tank, which were adjusted to contain ammonia concentrations of $0,0.1,0.2,0.4,0.8$, and $1.6 \mathrm{mg} / \mathrm{L}$ in advance. During the four weeks, dead and non-adhesive individuals were eliminated from each tank, and the number of surviving and sticking individuals was recorded. To identify the non-adhesive individuals, we carefully pushed the $H$. discus hannai using a glass rod, and those that moved were considered non-adhesive. The survival rate analysis was performed using the Kaplan-Meier survival method and log-rank test.

Survival rates $(\%)=(\mathrm{A} / \mathrm{B}) \times 100$

A, Number of surviving individuals attached to the substrate

$B$, Number of all individuals participating in the experiment

\section{Growth performance}

In two-week intervals, the growth performance of the H. discus hannai was determined by measuring the specific growth rate (SGR) and DISL ( $\mu \mathrm{m} /$ day). The calculations were done according to the following formulas:

$$
\begin{aligned}
\operatorname{SGR}(\% / \text { day })= & {[\text { In }(\text { final weight })-\text { In }(\text { initial weight })] / } \\
& (\text { days }) \times 100 \\
\operatorname{DISL}(\mu \mathrm{m} / \text { day })= & {[(\text { final mean shell length })-(\text { initial mean }} \\
& \text { shell length })] /(\text { days }) \times 1,000
\end{aligned}
$$

\section{Antioxidant response analysis}

Hepatopancreas and gill tissues were used to analyze the antioxidant response. Each tissue was excised and homogenized with 10 volumes of ice-cold homogenization buffer using a Teflon-glass homogenizer (099CK4424, Glass-Col, Darmstadt, Germany). The homogenate was centrifuged at $10,000 \times \mathrm{g}$ for 30 $\min$ at $4{ }^{\circ} \mathrm{C}$, and the supernatants were extracted. After supernatant extraction, the samples were stored at $-70^{\circ} \mathrm{C}$ until the antioxidant response analysis. SOD activity was measured using the SOD Assay kit (Dojindo Molecular Technologies, Rockville, MD, USA) with a $50 \%$ inhibitor rate for the reduction reaction of WST-1. SOD was defined as the amount of the enzyme in $20 \mu \mathrm{L}$ of sample solution that inhibits the reduction reaction of WST-1 with superoxide anions. CAT activity was measured using hydrogen peroxide as a substrate, and the absorbance was decreased by reducing hydrogen peroxide at a wavelength of 240 $\mathrm{nm}$ using a spectrophotometer. The unit of CAT activity was expressed as nmol by reducing hydrogen peroxide by reacting 1 $\mathrm{mg}$ of protein per min. The protein content was measured using a BioRad kit (BioRad, Herculanes, CA, USA) using the Bradford method and measured at $540 \mathrm{~nm}$ on a spectrophotometer using bovine serum albumin (BSA) as a standard protein.

\section{Immune response analysis}

The hemolymph was collected from the hemolymph sinus with an EDTA (50 mM EDTA in PBS, pH 7.6)-treated syringe to prevent entanglement of the hemocytes. The supernatant was then centrifuged (Mikro 22R, Hettich Zentrifugen, Tuttlingen, Germany) at $1,200 \mathrm{rpm}$ at $4{ }^{\circ} \mathrm{C}$ for $10 \mathrm{~min}$ and stored at $-70^{\circ} \mathrm{C}$ until the immune response analysis. PO and LZM activity were analyzed using hemolymph enzyme. PO activity was determined according to the methods described by Asokan et al. (1997). In brief, $2 \mathrm{mM}$ L-DOPA was added to $0.1 \mathrm{M}$ phosphate buffer ( $\mathrm{pH}$ 6.0) and mixed with the sample. The absorbance was measured 
at $490 \mathrm{~nm}$ for $10 \mathrm{~min}$, and the change of $0.001 \mathrm{in} 1 \mathrm{~min}$ was defined as the absorbance value (unit / ( $\mathrm{min} \cdot \mathrm{mg}$ protein)). LZM activity was measured using Micrococcus lysodeikticus (0.3 mg/ mL, 0.05 PBS buffer, pH 6.0; Sigma-Aldrich), which was previously used as a substrate in the method described by Hutchinson \& Manning (1996) . The standard curve was constructed using hen-egg white lysozyme (Sigma-Aldrich), the absorbance change was measured at $450 \mathrm{~nm}$ for $10 \mathrm{~min}$, and the active unit of lysozyme was expressed as unit/(min $\cdot \mathrm{mg}$ protein).

\section{Statistical analysis}

Statistical analyses were performed using the SPSS 12.0/PC + statistical package (SPSS, Chicago, IL, USA). Significant differences between the groups were confirmed using one-way ANOVA and Duncan's multiple comparison test or Student's $t$-test (Duncan, 1955 ) for both groups. The significance level of the statistical results was set at $p<0.05$.

\section{Results}

\section{Survival rates}

The survival rates of $H$. discus hannai are shown in Fig. 1. There was no death of $H$. discus hannai in ammonia concentrations below $0.8 \mathrm{mg} / \mathrm{L}$ during the four weeks of the study. Survival rates above 95\% were observed for all ammonia concentrations, but there was no significant difference in the log-rank test (Mantel-Cox), as the $p$-value was greater than 0.05 .

\section{Growth performance}

The growth performance of the $H$. discus hannai is shown in Fig. 2. The SGR significantly decreased at ammonia concentrations of $0.8 \mathrm{mg} / \mathrm{L}$ and $1.6 \mathrm{mg} / \mathrm{L}$ during the four weeks $(p<0.05)$. Conversely, there was no significant change in the DISL at all ammonia concentrations.

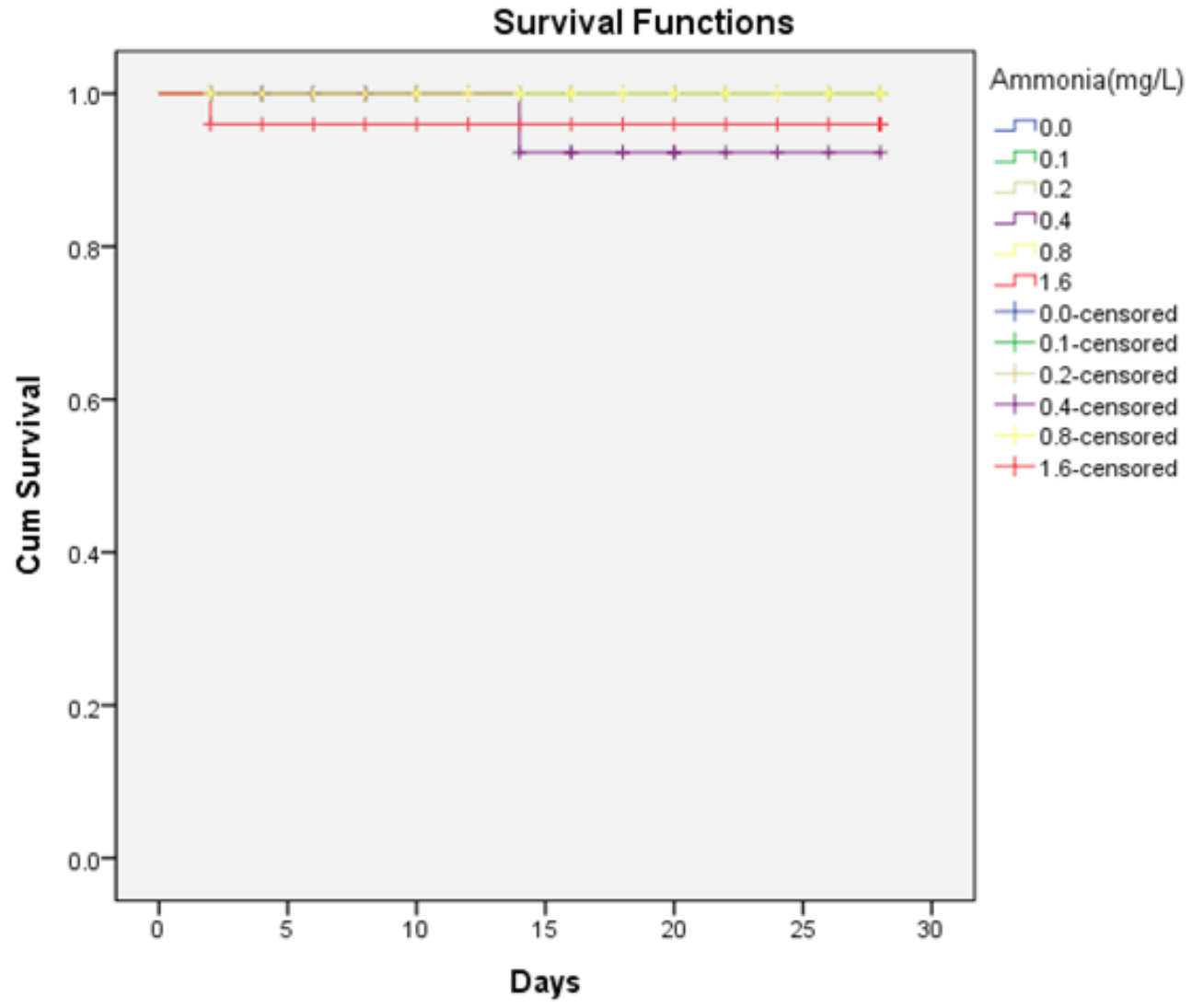

Fig. 1. Survival rates of Haliotis discus hannai exposed to the different concentration of ammonia for $\mathbf{4}$ weeks using Log Rank (Mantel-Cox). Chi-square $=1.317 ; d f=1 ; p$-value $=0.251$. 

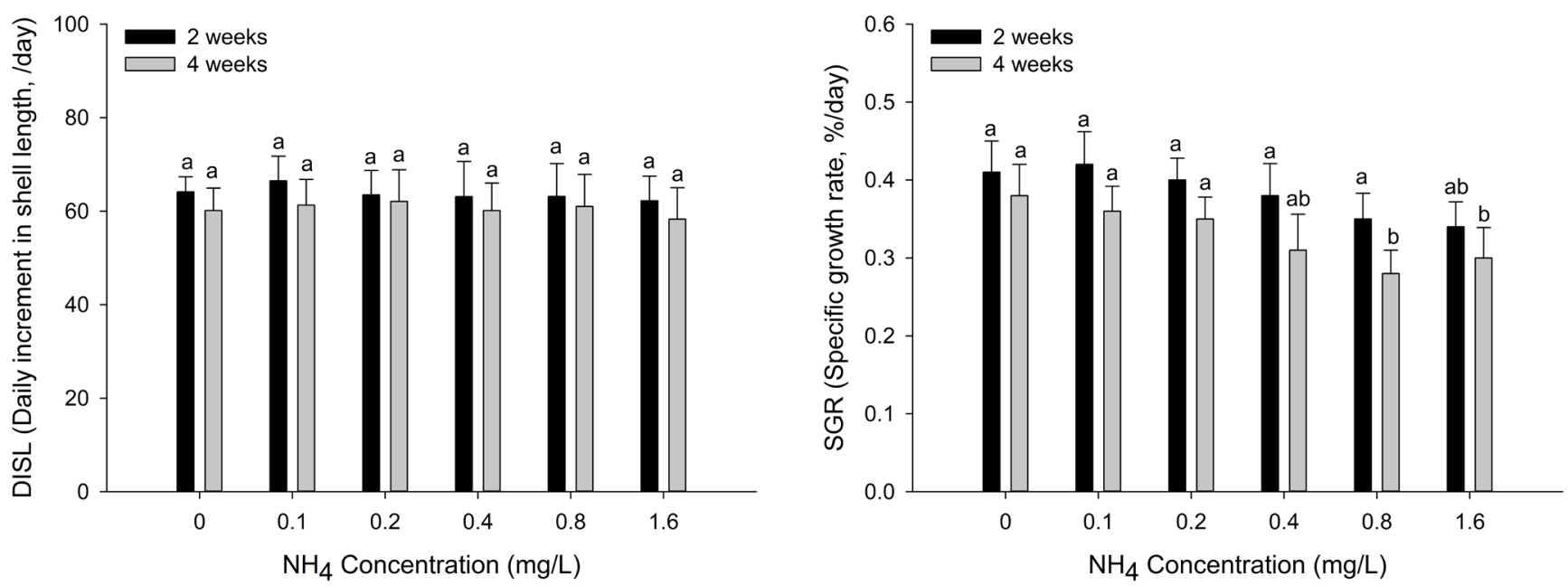

Fig. 2. Growth performance of Haliotis discus hannai exposed to the different concentration of ammonia for 4 weeks. Vertical bar denotes a standard error. Values with different superscripts are significantly different at 2 weeks and 4 weeks $(p<0.05)$ as determined by Duncan's multiple range test.

\section{Antioxidant responses}

Antioxidant responses (SOD and CAT) in the hepatopancreas and gill tissues of $H$. discus hannai are shown in Figs. 3 and 4. The SOD activity of hepatopancreas tissues was significantly increased at ammonia concentrations over $0.8 \mathrm{mg} / \mathrm{L}$ at two weeks and over $0.2 \mathrm{mg} / \mathrm{L}$ at four weeks $(p<0.05)$. CAT activity in the hepatopancreas showed a significant increase at ammonia concentrations above $0.8 \mathrm{mg} / \mathrm{L}$ at two and four weeks $(p<0.05)$. SOD activity of gill tissues was significantly increased at the 0.4 $\mathrm{mg} / \mathrm{L}$ and $1.6 \mathrm{mg} / \mathrm{L}$ ammonia concentrations at four weeks $(p<$ $0.05)$. CAT activity of gill tissues significantly increased at ammonia concentrations over $0.8 \mathrm{mg} / \mathrm{L}$ at four weeks $(p<0.05)$.

\section{Immune response}

Immune responses (PO and LZM) in the hemolymph tissues of H. discus hannai are shown in Fig. 5. PO activity was significantly increased at ammonia concentrations over $0.8 \mathrm{mg} / \mathrm{L}$ at two and four weeks $(p<0.05)$. LZM activity significantly increased at ammonia concentrations over $0.8 \mathrm{mg} / \mathrm{L}$ at two weeks and over $0.4 \mathrm{mg} / \mathrm{L}$ at four weeks $(p<0.05)$.

\section{Discussion}

Ammonia exists in aquatic environments, though an appropriate concentration must be maintained to support living organisms. In high-density aquafarms, the ammonia concentration is generally much higher than that in the natural environment. The alteration of environmental conditions can cause toxicity and induce changes in growth rate, physiological functions, and antioxidant and immune responses (Kim et al., 2019; Morash and Alter, 2016). Ammonia exposure has an adverse effect on the growth performance of abalones by decreasing food consumption and increasing oxygen consumption (Cheng et al., 2004; Harris et al., 1998). Chronic ammonia exposure causes a low growth rate and, consequently, death in abalones (Huchette et al., 2003). Therefore, it is important to maintain ammonia concentrations below toxic levels to ensure the optimal growth of abalones (Reddy-Lopata et al., 2006). In our biweekly measurements, SGR was significantly decreased at ammonia concentrations over $0.8 \mathrm{mg} / \mathrm{L}$ in $H$. discus hannai, which was consistent with the influence of ammonia exposure.

Aquatic organisms have antioxidant defense systems to protect themselves from oxidative stress by maintaining the balance between ROS production and antioxidant defense (Cheng et al., 2015). In the antioxidant defense system, SOD converts ROS into oxygen and hydrogen peroxide, and CAT catalyzes the conversion of hydrogen peroxide into water and oxygen. Both SOD and CAT play important roles in maintaining the antioxidant balance by eliminating ROS. These changes in antioxidant enzyme activities can be used as biomarkers of environmental stress (Hegazi et al., 2010). Exposure to ammonia is considered an environmental stress on aquatic organisms 

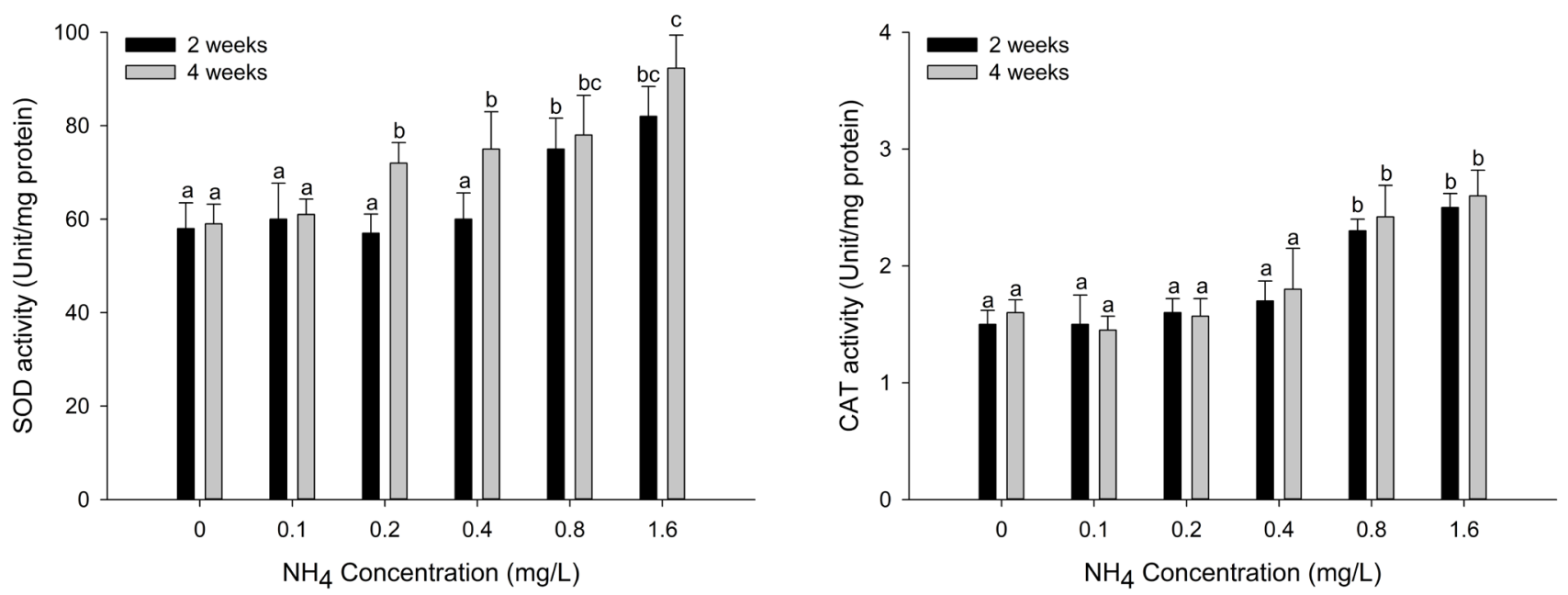

Fig. 3. SOD and CAT activity in hepatopancreas of Haliotis discus hannai exposed to the different concentration of ammonia for 4 weeks. Vertical bar denotes a standard error. Values with different superscripts are significantly different at 2 weeks and 4 weeks $(p<0.05)$ as determined by Duncan's multiple range test. SOD, superoxide dismutase; CAT, catalase.
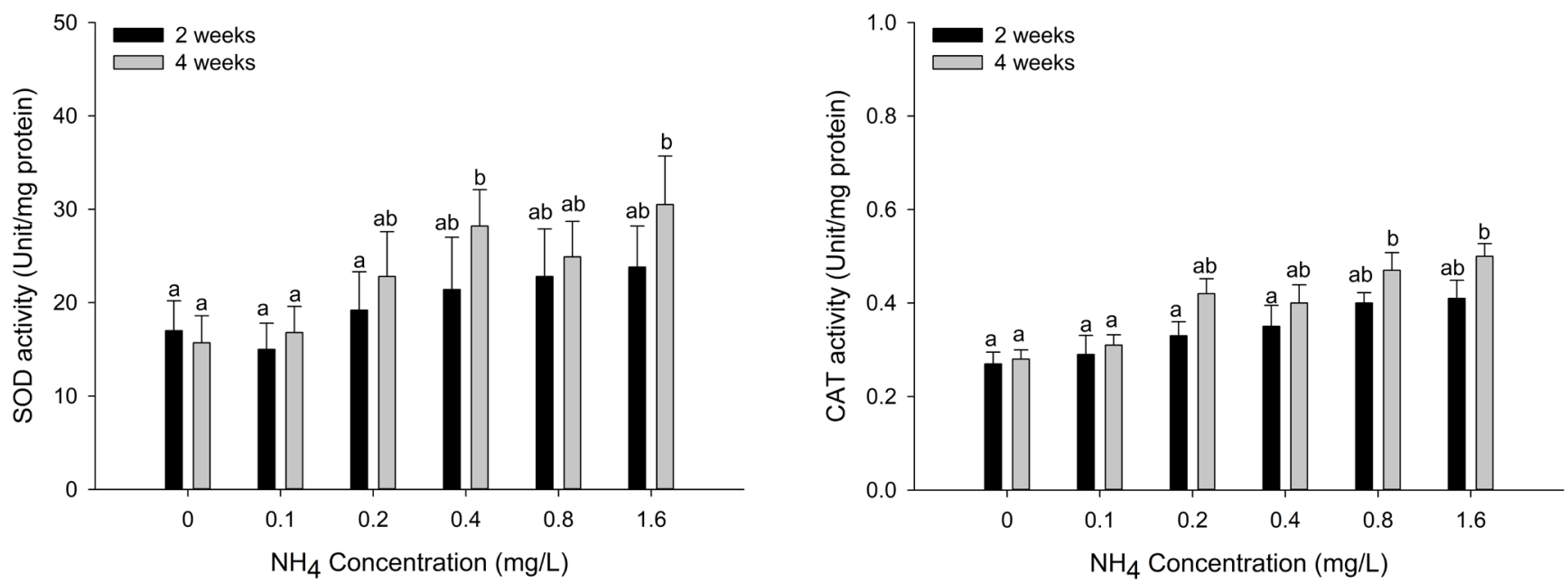

Fig. 4. SOD and CAT activity in gill of Haliotis discus hannai exposed to the different concentration of ammonia for $\mathbf{4}$ weeks. Vertical bar denotes a standard error. Values with different superscripts are significantly different at 2 weeks and 4 weeks $(p<0.05)$ as determined by Duncan's multiple range test. SOD, superoxide dismutase; CAT, catalase.

because exposure to ammonia can increase the production of ROS. In general, under normal conditions, ROS can be eliminated quickly by antioxidant enzymes; however, under high concentrations of ammonia, large amounts of ROS cannot be eliminated immediately, which causes an imbalance between ROS and antioxidant enzymes (Zhang et al., 2020). Liang et al. (2016) reported that SOD activity in the hepatopancreas of
Litopenaeus vannamei exposed to ammonia was significantly decreased, indicating that excessive ROS induced the inhibition of antioxidant enzymes and lost a compensatory mechanism due to excessive ROS. By contrast, Hegazi et al. (2010) reported that the activities of SOD and CAT in the liver and muscle were significantly increased in Oreochromis niloticus exposed to ammonia. Kim et al. (2019) reported that SOD and CAT levels in 

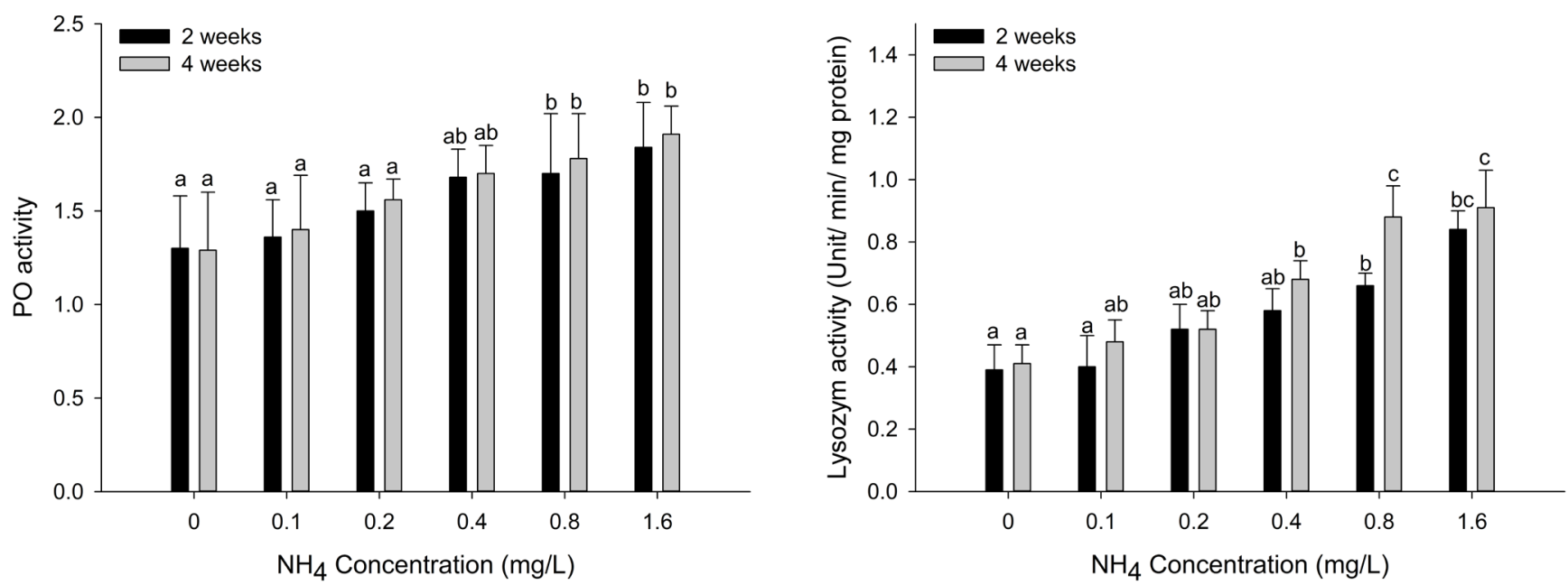

Fig. 5. PO and LZM activity in hemolymph of Haliotis discus hannai exposed to the different concentration of ammonia for 4 weeks. Vertical bar denotes a standard error. Values with different superscripts are significantly different at 2 weeks and 4 weeks ( $p<$ 0.05 ) as determined by Duncan's multiple range test. PO, phenoloxidase; LZM, lysozyme.

the liver and kidney of Parlichthys olivaceus exposed to ammonia were significantly increased. In addition, Kim et al. (2015) reported that SOD and CAT in the liver of Sebastes schlegelii exposed to ammonia significantly increased biweekly over four weeks. The authors argued that the increase in antioxidant enzyme activity was a defense mechanism for reducing excessive ROS. In our comprehensive results, both SOD and CAT in the hepatopancreas and gills of $H$. discus hannai were significantly increased after $0.8 \mathrm{mg} / \mathrm{L}$ ammonia exposure. We speculate that the increase in both SOD and CAT activity appears to be an adaptive response to remove excess ROS production during the ammonia exposure period.

Innate immune responses in abalones are more important than adaptive immune responses due to the absence of an adaptive immune system (Bathige et al., 2014; Jiang et al., 2013). PO activity in the hemolymph is considered the main component of the invertebrate immune system and is used to assess the impact of environmental stressors on the invertebrate immune system (Chen et al., 2005; Cui et al., 2017). Many studies have investigated the PO activity of invertebrates exposed to ammonia as an immune parameter. Cheng et al. (2004) reported that the PO activity of $H$. diversciolor supertexta was significantly decreased at 1.08, 3.16, 5.37, and $10.34 \mathrm{mg} / \mathrm{L}$ ammonia. The PO activity of $L$. vannamei exposed to ammonia was significantly decreased (Chen et al., 2012; Cui et al., 2017; Liu and Chen, 2004; Zhang et al., 2018), although it increased gradually as the ammonia concentration increased (Lingxu et al., 2004). In our study, the PO activity in $H$. discus hannai exposed to 0.8 and $1.6 \mathrm{mg} / \mathrm{L}$ ammonia was significantly increased at two and four weeks. It seems that the PO activity in invertebrates exposed to ammonia varies with different factors, including environmental conditions, invertebrate species, exposure concentration, and time. In addition to PO activity, LZM activity contributes to invertebrate innate immunity against bacterial invasion and is known to exist in the hemolymph, gills, mantles, and digestive organs (Ding et al., 2011). Duan et al. (2017) reported that the LZM activity of $L$. vannamei was significantly increased under ammonia stress. Qin et al. (2019) also observed that ammonia exposure induced a significant increase in LZM in Eriocheir sinensis. By contrast, Yue et al. (2010) reported that ammonia exposure reduced lysozyme mRNA expression levels in Portunus trituberculatus, which inhibited immune responses against disease outbreaks. Toxicants can stimulate or inhibit immune responses by responding to the toxicants (Kim et al., 2017). Our results showed that ammonia exposure over $0.8 \mathrm{mg} / \mathrm{L}$ induced a significant increase in LZM activity in H. discus hannai, which seemed to be the result of a response to ammonia toxicants.

Given the results of our study, ammonia concentrations greater than $0.8 \mathrm{mg} / \mathrm{L}$ acted as an environmental stressor to $H$. discus hannai, resulting in significant alterations in growth performance (SGR), antioxidant responses (SOD and CAT), and immune responses (PO and LZM activity) but not survival rate. 
Although the toxicity of ammonia on aquatic animals has been researched for a long time, there is insufficient research on the toxic effects of ammonia on $H$. discus hannai. The data obtained in this study can be used to evaluate the effects of ammonia toxicity on $H$. discus hannai.

\section{Competing interests}

No potential conflict of interest relevant to this article was reported.

\section{Funding sources}

Not applicable.

\section{Acknowledgements}

This work was supported by a Research Grant of Pukyong National University (2019).

\section{Availability of data and materials}

Upon reasonable request, the datasets of this study can be available from the corresponding author.

\section{Ethics approval and consent to participate}

This article does not require IRB/IACUC approval because there are no human and animal participants.

\section{References}

Asokan R, Arumugam M, Mullainadhan P. Activation of prophenoloxidase in the plasma and haemocytes of the marine mussel Perna viridis Linnaeus. Dev Comp Immunol. 1997;21:1-12.

Bachali S, Jager M, Hassanin A, Schoentgen F, Jollès P, Fiala-Medioni A, et al. Phylogenetic analysis of invertebrate lysozymes and the evolution of lysozyme function. J Mol Evol. 2002;54:652-64.

Bathige SDNK, Umasuthan N, Whang I, Lim BS, Won SH, Lee J. Antibacterial activity and immune responses of a molluscan macrophage expressed gene- 1 from disk abalone, Haliotis discus discus. Fish Shellfish Immunol. 2014;39:263-72.

Chen H, Mai K, Zhang W, Liufu Z, Xu W, Tan B. Effects of dietary pyridoxine on immune responses in abalone, Haliotis discus hannai Ino. Fish Shellfish Immunol. 2005;19:241-52.

Chen YY, Sim SS, Chiew SL, Yeh ST, Liou CH, Chen JC. Dietary administration of a Gracilaria tenuistipitata extract produces protective immunity of white shrimp Litopenaeus vannamei in response to ammonia stress. Aquaculture. 2012;370:26-31.

Cheng CH, Yang FF, Ling RZ, Liao SA, Miao YT, Ye CX, et al. Effects of ammonia exposure on apoptosis, oxidative stress and immune response in pufferfish (Takifugu obscurus). Aquat Toxicol. 2015;164:61-71.

Cheng W, Hsiao IS, Chen JC. Effect of ammonia on the immune response of Taiwan abalone Haliotis diversicolor supertexta and its susceptibility to Vibrio parahaemolyticus. Fish Shellfish Immunol. 2004;17:193-202.

Cook PA. The worldwide abalone industry. Mod Econ. 2014;5:1181-6.

Cui Y, Ren X, Li J, Zhai Q, Feng Y, Xu Y, et al. Effects of ammonia-N stress on metabolic and immune function via the neuroendocrine system in Litopenaeus vannamei. Fish Shellfish Immunol. 2017;64:270-5.

Ding J, Li J, Bao Y, Li L, Wu, F, Zhang G. Molecular characterization of a mollusk chicken-type lysozyme gene from Haliotis discus hannai Ino, and the antimicrobial activity of its recombinant protein. Fish Shellfish Immunol. 2011;30:163-72.

Duan Y, Zhang Y, Dong H, Wang Y, Zheng X, Zhang J. Effect of dietary Clostridium butyricum on growth, intestine health status and resistance to ammonia stress in Pacific white shrimp Litopenaeus vannamei. Fish Shellfish Immunol. 2017;65:25-33.

Duncan DB. Multiple range and multiple F tests. Biometrics. 1955;11:1-42.

Harris JO, Maguire GB, Edwards S, Hindrum SM. Effect of ammonia on the growth rate and oxygen consumption of juvenile greenlip abalone, Haliotis laevigata Donovan. Aquaculture. 1998;160:259-72.

Hegazi MM, Attia ZI, Ashour OA. Oxidative stress and antioxidant enzymes in liver and white muscle of Nile tilapia juveniles in chronic ammonia exposure. 2010;99;118-25.

Huchette SMH, Koh CS, Day RW. Growth of juvenile blacklip abalone (Haliotis rubra) in aquaculture tanks: effects of density and ammonia. Aquaculture. 2003;219:457-70.

Hutchinson TH, Manning MJ. Seasonal trends in serum lysozyme activity and total protein concentration in dab (Limanda limanda L.) sampled from Lyme Bay, UK. Fish Shellfish Immunol. 1996;6:473-82.

Jiang G, Yu R, Zhou M. Modulatory effects of ammonia-N on the immune system of Penaeus japonicus to virulence of white spot syndrome virus. Aquaculture. 2004;241:61-75.

Jiang HF, Liu XL, Chang YQ, Liu MT, Wang GX. Effects of di- 
etary supplementation of probiotic Shewanella colwelliana WA64, Shewanella olleyana WA65 on the innate immunity and disease resistance of abalone, Haliotis discus hannai Ino. Fish Shellfish Immunol. 2013;35:86-91.

Kim JH, Kang YJ, Kim KI, Kim SK, Kim JH. Toxic effects of nitrogenous compounds (ammonia, nitrite, and nitrate) on acute toxicity and antioxidant responses of juvenile olive flounder, Paralichthys olivaceus. Environ Toxicol Pharmacol. 2019;67:73-8.

Kim JH, Park HJ, Hwang IK, Han JM, Kim DH, Oh CW, et al. Toxic effects of juvenile sablefish, Anoplopoma fimbria by ammonia exposure at different water temperature. Environ Toxicol Pharmacol. 2017;54:169-76.

Kim SH, Kim JH, Park MA, Hwang SD, Kang JC. The toxic effects of ammonia exposure on antioxidant and immune responses in Rockfish, Sebastes schlegelii during thermal stress. Environ Toxicol Pharmacol. 2015;40:954-9.

Le Clec'h W, Anderson TJC, Chevalier FD. Characterization of hemolymph phenoloxidase activity in two Biomphalaria snail species and impact of Schistosoma mansoni infection. Parasites Vectors. 2016;9:1-11.

Li M, Chen L, Qin JG, Li E, Yu N, Du Z. Growth performance, antioxidant status and immune response in darkbarbel catfish Pelteobagrus vachelli fed different PUFA/vitamin E dietary levels and exposed to high or low ammonia. Aquaculture. 2013;406:18-27.

Li M, Gong S, Li Q, Yuan L, Meng F, Wang R. Ammonia toxicity induces glutamine accumulation, oxidative stress and immunosuppression in juvenile yellow catfish Pelteobagrus fulvidraco. Comp Biochem Physiol C Toxicol Pharmacol. 2016;183:1-6.

Liang Z, Liu R, Zhao D, Wang L, Sun M, Wang M, et al. Ammonia exposure induces oxidative stress, endoplasmic reticulum stress and apoptosis in hepatopancreas of pacific white shrimp (Litopenaeus vannamei). Fish Shellfish Immunol. 2016;54:523-8.

Lingxu J, Luqing P, Guoqiang X. Effects of ammonia-N on immune parameters of white shrimp Litopenaeus vannamei. J Fish Sci China. 2004;11:537-41.

Liu CH, Chen JC. Effect of ammonia on the immune response of white shrimp Litopenaeus vannamei and its susceptibility to Vibrio alginolyticus. Fish Shellfish Immunol. 2004;16:321-34.

Min EY, Cha YJ, Kang JC. Effects of waterborne nickel on the physiological and immunological parameters of the Pacific abalone Haliotis discus hannai during thermal stress. Environ Sci Pollut Res. 2015;22:13546-55.

Miron DDS, Moraes B, Becker AG, Crestani M, Spanevello R, Loro VL, et al. Ammonia and $\mathrm{pH}$ effects on some metabolic parameters and gill histology of silver catfish, Rhamdia quelen (Heptapteridae). Aquaculture. 2008;277:192-6.

Morash AJ, Alter K. Effects of environmental and farm stress on abalone physiology: perspectives for abalone aquaculture in the face of global climate change. Rev Aquac. 2016;8;342-68.

Nam SE, Haque MN, Lee JS, Park HS, Rhee JS. Prolonged exposure to hypoxia inhibits the growth of Pacific abalone by modulating innate immunity and oxidative status. Aquat Toxicol. 2020;227:105596.

Naylor MA, Kaiser H, Jones CLW. The effect of free ammonia nitrogen, $\mathrm{pH}$ and supplementation with oxygen on the growth of South African abalone, Haliotis midae L. in an abalone serial-use raceway with three passes. Aquac Res. 2014;45:213-24.

Pan CH, Chien YH, Wang YJ. Antioxidant defence to ammonia stress of characins (Hyphessobrycon eques Steindachner) fed diets supplemented with carotenoids. Aquac Nutr. 2011;17:258-66.

Qin F, Shen T, Yang H, Qian J, Zou D, Li J, et al. Dietary nano cerium oxide promotes growth, relieves ammonia nitrogen stress, and improves immunity in crab Eriocheir sinensis. Fish Shellfish Immunol. 2019;92:367-76.

Reddy-Lopata K, Auerswald L, Cook P. Ammonia toxicity and its effect on the growth of the South African abalone Haliotis midae Linnaeus. Aquaculture. 2006:261:678-87.

Wickramanayake MVKS, Dahanayake PS, Hossain S, Heo GJ. Antimicrobial resistance of pathogenic Aeromonas spp. isolated from marketed Pacific abalone (Haliotis discus hannai) in Korea. J Appl Microbiol. 2020;128:606-17.

Yao T, Zhao MM, He J, Han T, Peng W, Zhang H, et al. Gene expression and phenoloxidase activities of hemocyanin isoforms in response to pathogen infections in abalone Haliotis diversicolor. Int J Biol Macromol. 2019;129:538-51.

Yue F, Pan L, Xie P, Zheng D, Li J. Immune responses and expression of immune-related genes in swimming crab Portunus trituberculatus exposed to elevated ambient ammonia-N stress. Comp Biochem Physiol A Mol Integr Physiol. 2010;157:246-51.

Zhang M, Li M, Wang R, Qian Y. Effects of acute ammonia toxicity on oxidative stress, immune response and apoptosis of juvenile yellow catfish Pelteobagrus fulvidraco and the 
mitigation of exogenous taurine. Fish Shellfish Immunol. 2018;79:313-20.

Zhang T, Yan Z, Zheng X, Wang S, Fan J, Liu Z. Effects of acute ammonia toxicity on oxidative stress, DNA damage and apoptosis in digestive gland and gill of Asian clam (Corbicula fluminea). Fish Shellfish Immunol. 2020;99:514-25. 